\title{
Chronic Stress and Glucocorticoid Receptor Resistance in Asthma
}

\author{
María Laura Palumbo, $\mathrm{PhD}^{1}$; Andrés Prochnik, $\mathrm{MSc}^{2}$; \\ Miriam Ruth Wald, $\mathrm{PhD}^{2}$; and Ana María Genaro, $\mathrm{PhD}^{2,3}$ \\ ${ }^{1}$ Centro de Investigaciones y Transferencia del Noroeste de la Provincia de Buenos Aires \\ (UNNOBA-UNSADA-CONICET), Junín, Argentina; ${ }^{2}$ Instituto de Investigaciones Bio- \\ médicas (UCA-CONICET), Buenos Aires, Argentina; and ${ }^{3}$ Departamento de Farmacología, \\ Facultad de Medicina, UBA Paraguay, Buenos Aires, Argentina
}

\section{ABSTRACT}

Purpose: Chronic and persistent exposure to negative stress can lead to adverse consequences on health. Particularly, psychosocial factors were found to increase the risk and outcome of respiratory diseases like asthma. Glucocorticoids (GCs) are the most efficient anti-inflammatory therapy for asthma. However, a significant proportion of patients don't respond adequately to GC administration. GC sensitivity is modulated by genetic and acquired disease-related factors. Additionally, it was proposed that endogenous corticosteroids may limit certain actions of synthetic GCs, contributing to insensitivity. Psychological and physiological stresses activate the hypothalamic-pituitary-adrenal axis, increasing cortisol levels. Here, we review the mechanism involved in altered GC sensitivity in asthmatic patients under stressful situations. Strategies for modulation GC sensitivity and improving GC therapy are discussed.

Methods: PubMed was searched for publications on psychological chronic stress and asthma, GC resistance in asthma, biological mechanisms for GC resistance, and drugs for steroid-resistant asthma, including highly potent GCs.

Findings: GC resistance in patients with severe disease remains a major clinical problem. In asthma, experimental and clinical evidence suggests that chronic stress induces inflammatory changes, contributing to a worse GC response. GC resistant patients can be treated with other broad-spectrum anti-inflammatory drugs, but these generally have major side effects. Different mechanisms of GC resistance have been described and might be useful for developing new therapeutic strategies against it.
Novel drugs, such as highly potent GCs, phosphoinositide 3-kinase-delta inhibitors that reestablish histone deacetylase-2 function, decrease of GC receptor phosphorylation by p38 mitogenactivated protein kinase inhibitors, or phosphatase activators, are currently in clinical development and might be combined with GC therapy in the future. Furthermore, microRNAs (small noncoding RNA molecules) operate as posttranscriptional regulators, providing another level of control of GC receptor levels. Empirical results allow postulating that the detection and study of microRNAs might be a promising approach to better characterize and treat asthmatic patients.

Implications: Many molecular and cellular pathobiological mechanisms are responsible of GC resistance. Therefore detecting specific biomarkers to help identify patients who would benefit from new therapies is crucial. Stress consitutes a negative aspect of current lifestyles that increase asthma morbidity and mortality. Adequate stress management could be an important and positive intervention. (Clin Ther. 2020; 42:XXX-XXX) (c 2020 Elsevier HS Journals, Inc. (Clin Ther. xxxx;xxx:xxx) (c) 2020 Elsevier Inc.

Key words: asthma, chronic stress, glucocorticoid resistance, pharmacologic strategies.

Accepted for publication March 4, 2020

https://doi.org/10.1016/j.clinthera.2020.03.002

0149-2918/\$ - see front matter

(c) 2020 Elsevier Inc. 


\section{INTRODUCTION}

In the last decades, stress has become an important aspect of modern life. Exposure to adverse situations affects virtually everyone worldwide. Stress is defined as any situation capable of perturbing the physiological or psychological homeostasis. Although response to stress is a necessary survival mechanism, prolonged stress can have several repercussions affecting behavioral, endocrine, and immunologic parameters. ${ }^{1}$ Many of these effects are mediated through stress actions on the immune system..$^{2-5}$ In an interesting review, Dhabhar ${ }^{6}$ described the different effects that stress has on immune response, taking into account key factors such as stress duration and its timing regarding the immune response activation and course. Whether the stress effect on immune response has a beneficial or harmful effect on health depends on the end-effect of the immune response. Thus, short-term stress can be favorable by enhancing the immune response in wound healing and vaccination but promotes pathological, pro- inflammatory, or autoimmune responses. In contrast, chronic stress can suppress protective immune responses and/or exacerbate pathological ones. Chronic psychological stress has been associated with a higher risk of depression, cardiovascular disease, diabetes, autoimmune diseases, upper respiratory tract infections, and poorer wound healing. ${ }^{7}$

Asthma is a highly prevalent, chronic respiratory condition characterized by reversible airflow obstruction, airway hyperresponsiveness, and airway inflammation producing breathlessness, coughing, and wheezing. Currently, it is known that in asthma there is a complex interplay between inflammatory cells such as eosinophils, mast cells, basophils, dendritic cells and lymphocytes, and structural cells (namely epithelial cells, fibroblasts, and smooth muscle cells). The chronic airway inflammation has been associated with the accumulation and activation of inflammatory cells such as type 2 T-helper (Th2) cells that secrete interleukin (IL)-4, IL-5, IL-13, eosinophils, and mast cells within the bronchial mucosa. ${ }^{8}$

According to the World Health Organization (https://www.who.int/news-room/fact-sheets/detail/ asthma), 235 million people are living with asthma. Independently of asthma severity and despite optimal medical therapy, patients may experience acute exacerbations of symptoms and a loss of disease control. Asthma exacerbations are a major cause of disease morbidity, increases in health care costs, and, in some patients, a greater progressive loss of lung function. Inhaled corticosteroids, long-acting betaagonists, and biologic therapy reduce asthma exacerbations and improve disease control. However, when exacerbations occur, systemic corticosteroids remain the primary intervention when bronchodilator therapy is not effective.

It is known that GCs in pharmacologic doses have anti-inflammatory and immunosuppressive properties, and synthetic GCs are widely prescribed for inflammation, autoimmune disorders, and malignancies of lymphoid origin treatment. However, a substantial proportion of patients do not adequately respond to GC therapy. The biologic effects of GC are determined not only by their concentration but also by individual and tissue sensitivity to the hormone. ${ }^{10}$

In general, GC sensitivity refers to the response of a GC-responsive system to different concentrations of hormone, and it is dependent of GC receptor (GR) expression and affinity, and many intracellular mediators that can regulate the signal transduction cascade. Individual differences in GC sensitivity have been described in health and disease and are clinically relevant because they can influence both the outcome and the adverse effects of GC therapy. ${ }^{10}$ GC resistance, on the other hand, refers to a decrease in the sensitivity of immune cells to GC hormones that would normally end the inflammatory response. Evidence for GC resistance has been found mainly in rheumatoid arthritis, ${ }^{11}$ systemic lupus erythematosus, bronchial asthma, inflammatory bowel disease, and immune thrombocytopenia. ${ }^{12}$ GC resistance in patients with severe disease remains a major clinical problem. GC sensitivity can be modulated by genetic and acquired disease-related factors. ${ }^{13}$ In recent years, several lines of evidence have suggested that environmental factors such as cigarette smoke, exposure to bacterial toxins or allergens, viral infection, and chronic stress could influence GC response. ${ }^{13,14}$ It has been proposed that prolonged stressors result in GC resistance, which, in turn, interferes with appropriate inflammatory regulation. In particular, chronic stress exposure could be influencing asthma exacerbations and treatment response. ${ }^{14}$ 
The present article reviews the evidence supporting the participation of stress in asthma exacerbations and the mechanisms involved in altered GC sensitivity in this group of patients. Strategies for GC sensitivity modulation and therapy improvement are also discussed.

\section{MATERIALS AND METHODS}

PubMed was searched for publications on psychological chronic stress and asthma, GC resistance in asthma, molecular and cellular mechanism for GC resistance, and drugs for steroidresistant asthma, including highly potent GCs.

\section{MECHANISMS OF GC ACTIONS}

Exogenously administered GCs diffuse across the plasma membrane due to high lipophilicity. In the cytoplasm, GCs bind to the alpha subunit of the GR, which is part of a multiprotein complex with chaperone proteins. In the classic signal transduction pathway, GC binding induces a molecular rearrangement of the GR heterocomplex that results in subsequent homodimerization, nuclear translocation of the GC-GR complex, and interaction with specific DNA elements named GC response elements (GREs) modulating the gene transcription. The direction of the transcriptional response depends partially on the nature of the GRE. Positive GREs mediate transcriptional upregulation (transactivation), whereas negative GREs mediate transcriptional downregulation (cis-repression). Conversely, GC-GR can also regulate gene expression by physically interacting with other transcription factors such as nuclear factor kappa B $(\mathrm{NF}-\kappa \mathrm{B})$ and activator protein-1 (AP-1), a phenomenon called "transrepression."

Thus, GCs exert their anti-inflammatory and immunosuppressive effects through the induction of synthesis of several molecules such as lipocortin-1, secretory leukocyte inhibitory protein, an inhibitor of NF- $\kappa \mathrm{B}(\mathrm{I} \kappa \mathrm{B}-\alpha)$, an inhibitor of mitogen-activated protein kinase (MAPK) pathways (MKP1), GCinducible leucine zipper (GILZ) and antiinflammatory cytokines (IL-10, IL-12, and IL-1 receptor antagonists). Moreover, it inhibits the synthesis of inflammatory cytokines (IL-2, IL-3, IL-4, IL-5, IL-6, IL-8, IL-13, IL-15, tumor necrosis factor- $\alpha$ $[\mathrm{TNF}-\alpha]$, and granulocyte-macrophage colonystimulating factor), chemokines (CCL1, CCL5, CCL11, CXCL8, monocyte chemotactic protein-1, eotaxin, RANTES [regulated upon activation normal $T$ cell expressed and secreted], and macrophage inflammatory protein-1 $\alpha$ ); inflammatory enzymes (inducible nitric oxide [NO] synthase, inducible cyclo-oxygenase, and inducible phospholipase A2), inflammatory peptides (endothelin-1), and adhesion molecules (intercellular cell adhesion molecule 1 and vascular cell adhesion molecule 1). ${ }^{15}$ In addition, GCs have multiple effects that do not require GC-GR complex binding to GRE or direct protein-protein interactions and occur seconds to minutes after stimulation, namely nongenomic effects. ${ }^{16}$ Three mechanisms were described for nongenomic effects: nonspecific interactions of GCs with cellular membranes, mediated by the release of different chaperones; following binding of GC to the cytosolic GR; and specific interactions with a membrane-bound GR.

Finally, it was proposed that different physiological contexts result in a variety of signaling pathways activated in concomitance with GR signaling. ${ }^{17}$ These signaling pathways interacting with GRs can modify the sensitivity and efficacy of GC responses, with implications for physiology, diseases, and treatments. ${ }^{17}$

\section{CELLULAR AND MOLECULAR MECHANISMS INVOLVED IN CORTICOSTEROID RESISTANCE IN SEVERE ASTHMA}

Severe bronchial asthma is a very heterogeneous clinical syndrome in which the GC-resistant inflammatory nature is due to different cellular and molecular pathobiologic mechanisms called endotypes. ${ }^{18}$ This concept of disease is particularly important because defining different disease-driving mechanisms may provide insights for targeted and personalized treatment for each population with corticoid-resistant severe asthma.

Currently, the endotype of asthma is divided into Th2-high and Th2-low inflammation. The Th2-high endotype is characterized by airway eosinophil counts and increased Th2 inflammatory cytokines (eg, IL-4, IL-5, IL-13). Th2-high endotype eosinophilic asthma is often responsive to steroid therapy, but $10 \%-20 \%$ of these patients exhibit GC insensitivity. The Th2-low endotype patients have high airway neutrophil counts and type 17 T-helper (Th17) cytokines. This endotype is a less GCresponsive disease variant and has lower lung function clinically. ${ }^{19}$ However, this simplified 


\section{Clinical Therapeutics}

classification does not correctly reflect the underlying pathobiologic processes of GC-resistant inflammation in severe asthma. There are disease-associated mechanisms that could promote, sustain, and/or aggravate low steroid sensitivity within the population and even in the same individual over the time. In addition, a clustering analysis involving 112 clinical, physiologic, and inflammatory variables found that combined eosinophilic/neutrophilic inflammation may be a biomarker of the most severe form of asthma. ${ }^{20}$

The following discussion covers different cellular and molecular mechanisms that could be involved in GC resistance in severe asthma (Fig. 1).

\section{Genetic Susceptibility to GC Resistance}

There is evidence that GC resistance could have a genetic component. Hakonarson et $\mathrm{al}^{21}$ analyzed the gene expression profiles of freshly isolated peripheral blood mononuclear cells (PBMCs) from patients with GC-sensitive and GC-resistant asthma. The authors tested the effect of GCs in resting cells and cells stimulated with IL-1 $\beta$ and TNF- $\alpha$ combined. They found a panel of 11 genes that most accurately distinguished GC responders from nonresponders, predicting the GC response phenotype with $84 \%$ accuracy. $^{22}$ Moreover, a functional variant GCinduced transcript 1 gene (GLCCI1) was associated with a substantial reduction in the inhaled GC response in patients with asthma. ${ }^{23}$

\section{Changes in GR Expression}

The cellular GR expression levels have been correlated with the magnitude of the biologic effects induced by GCs. Diminished GR number and binding affinity were found in peripheral blood

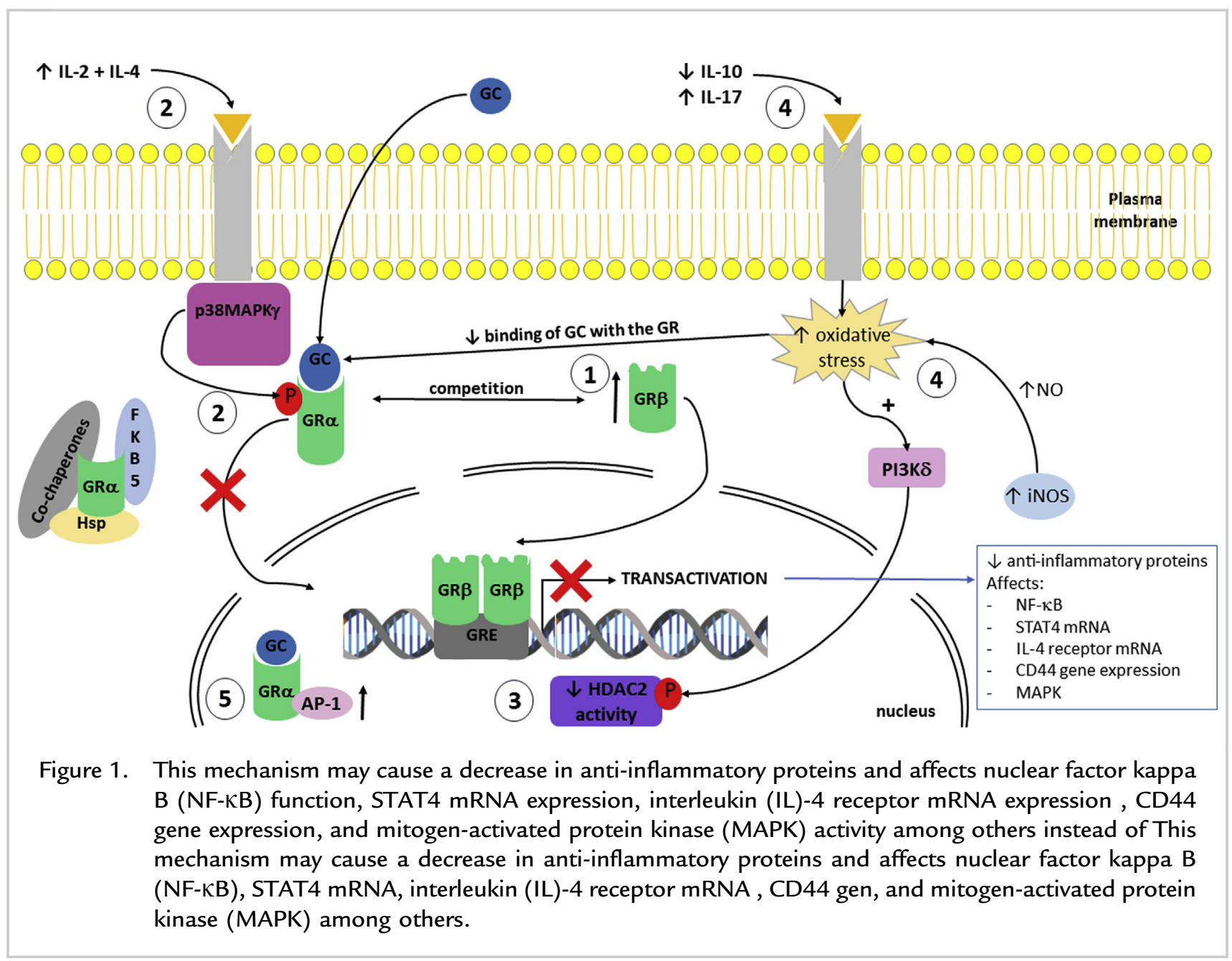


monocyte cells from patients with GC-resistant asthma. ${ }^{24}$ Most cell types showed a downregulation of the amount of GR upon GC exposure, probably as a mechanism to maintain GC homeostasis. Another level of fine adjustment GR levels is provided by microRNAs (miRs). miRs are a class of naturally occurring, small noncoding RNA molecules, $\sim 21$ to 25 nucleotides in length that operate as posttranscriptional regulators, reducing translation and increasing mRNA degradation. Some miRs, such as miR-18 and mi-124, decrease GR protein levels in the brain. ${ }^{25}$ In particular, it was shown that GC treatment induces expression of miR-124, which, in turn, could be downregulating GR- $\alpha$ in $T$ cells, limiting anti-inflammatory effects of GCs. ${ }^{26}$ Further investigations proved the involvement of $\mathrm{miR}$ in the inflammatory and immunological mechanisms of asthma genesis. ${ }^{27}$

\section{Increased Expression of GR- $\beta$ Isoforms}

Functional polymorphisms of the GR partially determine differences in sensitivity to GCs. In particular, GR- $\beta$ isoform is a nonligand-binding receptor, and it reportedly is a dominant-negative inhibitor of GR- $\alpha$ that competitively binds GREs, influencing transactivation. ${ }^{28}$ Several studies found augmented GR- $\beta$ gene expression in both infiltrating blood cells and in airway epithelial cells of patients with GC-insensitive asthma. ${ }^{29-31}$ Furthermore, RNA silencing of GR- $\beta$ mRNA in bronchoalveolar lavage macrophages of patients insensitive to GC increases transcriptional activity of GR- $\alpha{ }^{31}$ Vazquez-Tello et $\mathrm{al}^{32}$ showed that IL-17/IL-23 cytokines promoted GR- $\beta$ upregulation, which is associated with induced GC insensitivity in PBMCs. Conversely, GC resistance induced by IL-2/IL-4 was associated with decreased GR- $\alpha$ expression. ${ }^{24,32,33}$ These results support the possibility that Th-17 lymphocytes and associated cytokines have a role in the mechanism of steroid hyporesponsiveness in patients with severe asthma.

\section{Defective Nuclear Translocation and Binding Affinity}

GR can be phosphorylated at multiple serine/ threonine residues, and different phosphorylation patterns can alter its GC binding to receptor, stability, translocation to the nucleus, binding to DNA, and interaction with other proteins such as transcription factors and molecular chaperones. ${ }^{34}$ Several kinases have been identified as being capable of phosphorylating the GR (glycogen synthase kinase-3 $\beta$, MAPKs, and cyclin-dependent kinase). Cellular conditions modulate the activation of these signaling pathways, resulting in different GR phosphorylation patterns that modulate its transcriptional activity within cells. ${ }^{35}$

Bhavsar et $\mathrm{al}^{36}$ found a greater activation degree of p38 MAPK in alveolar macrophages from patients with asthma and GC insensitivity compared with those with normal response. In addition, a p38 MAPK inhibitor induced an increase of GC sensitivity in PBMCs from patients with severe asthma. $^{37}$ It was reported that IL-2 and IL-4 synergistically reduce nuclear translocation and binding affinity in $\mathrm{T}$ cells, orchestrated via the $\mathrm{p} 38$ MAPK pathway; this effect can be reversed by a p38 inhibitor. ${ }^{33}$ Similarly, MAPK c-Jun N-terminal kinase (JNK), which is activated by TNF- $\alpha$ and other proinflammatory cytokines, directly phosphorylates GR at Ser226 and inhibits GRE binding too. ${ }^{38}$ Moreover, it was reported that inhibition of the extracellular receptor kinase (ERK) pathway restored dexamethasone sensitivity in some GC-resistant $\mathrm{T}$ cells. ${ }^{39}$

Ubiquitination and sumoylation are other posttranslational GR modifications. Both induce GR degradation and consequently affect its transcriptional activity. ${ }^{40}$ Furthermore, in vitro GR may be nitrosylated by NO donors. This action results in reduced binding affinity for GC. ${ }^{41}$ In severe asthma, there is increased expression of inducible NO synthase, which produces large amounts of NO that, in turn, could reduce GC responsiveness.

\section{Altered Transcriptional Regulation}

Physical association with other transcription factors is one of the mechanisms that regulates GR transcriptional response. GR is able to interact with proinflammatory transcription factors, such as NF- $\kappa \beta$ and AP-1, inhibiting their activity and repressing inflammatory signaling pathways. ${ }^{42}$

It has been shown that overexpression of AP-1 contributes to GC resistance in patients with asthma. ${ }^{43} \mathrm{~A}$ possible mechanism for the AP-1 increase is the presence of the proinflammatory cytokine TNF- $\alpha$, which causes AP-1 activation through the JNK pathway. 


\section{Clinical Therapeutics}

Another important mechanism of GR transcriptional regulation involves modulation of DNA accessibility. Recruitment of histone deacetylase-2 (HDAC-2), allowing deacetylation and condensation of histones located in promoter regions of proinflammatory genes, is the major mechanism that inhibits their transcription. Reduced HDAC-2 activity was reported in patients in alveolar macrophages with refractory asthma and in the airways of patients with asthma who smoke. ${ }^{44}$ It was reported that oxidative and nitrative stress results in the formation of peroxynitrite, which, in turn, induces increased proteasomal degradation following ubiquitination. . $^{23,45}$

\section{GR RESISTANCE ASSOCIATED WITH EXTERNAL FACTORS THAT ALTER RECEPTOR BIOLOGY}

There is evidence suggesting that some external factors, including cigarette smoke, exposure to bacterial toxins, viral infection, allergen exposure, and lifestyle, could influence GC response by altering receptor biology (Fig. 2).

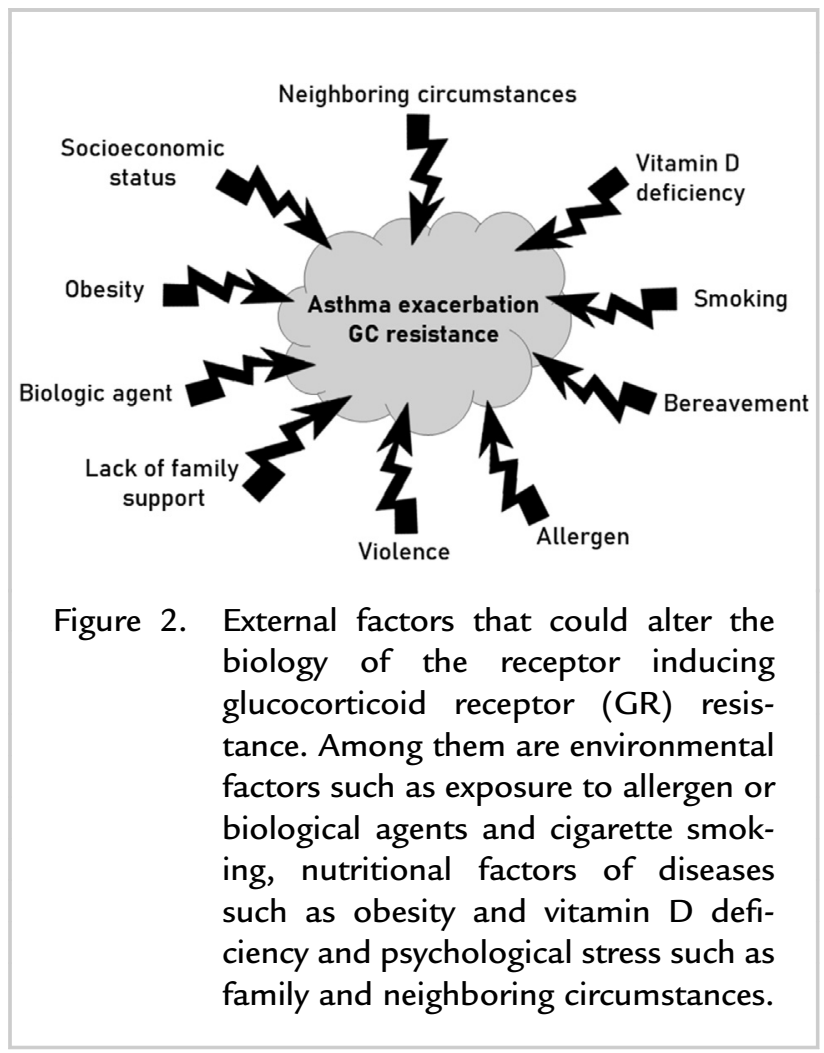

\section{Cigarette Smoking}

Cigarette smoking reportedly increases asthma incidence among adolescents, enhances asthma severity, and induces airway neutrophilia. ${ }^{46-48}$ Cigarette smoking also decreases the clinical response to inhaled and oral corticosteroids. ${ }^{49}$ It was proposed that cigarette smoking induces an oxidative stress that in turn affects nuclear cofactors. In fact, a reduction in HDAC-2 expression was found in the airways of patients with asthma who smoke. ${ }^{50}$ In addition, PBMCs from patients with asthma who smoke also have an elevated GR- $\beta$ to GR- $\alpha$ ratio. ${ }^{51}$

\section{Exposure to Allergen and Biological Agents}

Patients with severe allergic asthma require increased amounts of GC therapy to control their asthma during the pollen season. ${ }^{52}$ The effect of allergen exposure on GR function and GR-binding affinity in PBMCs from patients with atopic asthma was examined by Nimmagadda et al. ${ }^{53}$ The authors found a significant reduction in the GR-binding affinity in ragweed-allergic patients with asthma during ragweed pollen season compared with PBMCs obtained before and after ragweed season. These effects seem to be mediated by an increase in IL-2 and IL-4 cytokine levels. ${ }^{54}$

Moreover, recurrent exacerbations are triggered by respiratory viruses and constitute a serious problem in patients with asthma. ${ }^{54}$ Clinical and laboratory evidence indicates that GCs are strongly inefficient in treating virus-induced asthma exacerbations. ${ }^{55,56} \mathrm{It}$ has been reported that rhinovirus infection can reduce GR- $\alpha$ nuclear translocation and both transactivation and transrepression activities of GC in airway epithelial cells through a mechanism involving JNK and NF-kB pathway activation. ${ }^{57}$ Finally, it was reported that microbial superantigens induced GC resistance in $\mathrm{T}$ cells in vitro via activation of ERK pathways. $^{39,58}$

\section{Obesity}

A large body of robust epidemiologic data has revealed that obesity increases both asthma risk and asthma severity. ${ }^{59,60}$ In addition, pharmacologic trials showed that clinical responsiveness to inhaled GCs was diminished in overweight patients. ${ }^{61}$ High body mass index is associated with a blunted in vitro 
response to dexamethasone in overweight and obese patients with asthma. ${ }^{62}$

\section{Disease-Related Factors}

A proportion of patients have a deficient response to GCs due to tissue-specific resistance induced by disease-related factors. As described, several factors for this acquired GC resistance are associated with significant changes in the cellular microenvironment, such as oxidative stress, cytokine production, and increased P-glycoprotein-mediated drug efflux.

Oxidative and nitrative stress results in the formation of peroxynitrite, which in turn nitrates tyrosine residues on HDAC-2, leading to its inactivation, ubiquitination, and degradation. ${ }^{23}$ In addition, oxidative stress activates phosphoinositide 3-kinase (PI3K) that induces phosphorylation and inactivation of HDAC-2. ${ }^{45}$ This evidence suggests that oxidative stress might be an important mechanism of steroid resistance in patients with severe asthma. ${ }^{63}$

A deregulated production of cytokine was found in GC-resistant asthma. In patients with GC-resistant asthma, it was described as a defective production of IL-10 by regulatory $\mathrm{T}$ cells in response to GC. ${ }^{64,65}$ On the contrary, elevated levels of IL-17 and related cytokines produced by Th17 cells were reported in patients with severe asthma. ${ }^{66}$ IL-17 increases the expression of GR- $\beta$ expression in epithelial cells, suggesting a possible role for Th17-associated cytokines in the mechanism of steroid hyporesponsiveness in patients with asthma. ${ }^{32}$ As noted earlier, it was reported that IL-2 and IL-4 synergistically reduce nuclear translocation and binding affinity in T cells. ${ }^{33}$

Last but not least, vitamin D deficiency has been associated with reduced lung function, increased airway hyperresponsiveness, and reduced GC response, suggesting that vitamin $\mathrm{D}$ supplementation in patients with asthma may improve asthma severity and treatment response. ${ }^{67}$ In children with asthma, reduced vitamin D levels are associated with increased markers of allergy and asthma severity. ${ }^{68}$ Furthermore, the addition of vitamin $\mathrm{D}_{3}$ in combination with dexamethasone in the same study restored the ability of $\mathrm{CD}^{+}{ }^{+} \mathrm{T}$ cells from GC-resistant patients with asthma to release IL-10 at the same level as those seen in cells from GC-sensitive patients with asthma. ${ }^{69}$ Moreover, vitamin $\mathrm{D}_{3}$ was able to upregulate MKP-1 to repress p38 MAPK-mediated cytokine secretion in monocytes and macrophages.

\section{INFLUENCE OF STRESS EXPOSURE IN ASTHMA EXACERBATIONS AND GC RESISTANCE}

Currently, stress and emotional factors are considered important stimuli capable of disturbing the brain-endocrine-immune interaction, strongly implicated in morbidity and mortality in asthma. In a very interesting review, Ohno ${ }^{14}$ presents insights into the critical role of psychological stress in the development and exacerbation of allergic asthma, emphasizing the continuity from the central sensing of psychological stress to the enhanced eosinophilic airway inflammation.

Clinical studies have shown a relation between psychological stress and the exacerbation of asthma symptoms. ${ }^{70,71}$ According to a survey performed in 3085 patients, which searched for factors contributing to asthma exacerbation, emotional stress caused $10 \%-15 \%$ of the asthma exacerbation. Both acute $^{72-74}$ and chronic ${ }^{74,75}$ stress exposures have been associated with enhanced asthma exacerbations in children ${ }^{73,74}$ and adults. ${ }^{72,75,76}$

Sandberg et $\mathrm{al}^{74}$ reported that in children, harsh negative life events significantly increase the risk of experiencing more asthmatic episodes in upcoming weeks. The risk is enhanced if the child lives in conditions of chronic high stress. Furthermore, exposure to physiological stress has been found to strongly correlate with poor outcome for asthma, both in children and adults.

Psychological stress caused by domestic and neighboring circumstances ${ }^{78,79}$ such as bereavement ${ }^{80}$ and violence ${ }^{81,82}$ is frequently related to stress-induced asthma exacerbation. In a study of youths diagnosed with asthma aged 9-18 years, Chen et al ${ }^{79}$ investigated the influence of family support and neighborhood problems in asthma outcomes. This study found that a lack of family support was related to increased asthma symptoms and poorer pulmonary function through allergic inflammation. In addition, evidence was consistent with the hypothesis that greater neighborhood problems were related to greater asthma symptoms by providing role models for maladaptive health behaviors, such as smoking. However, peer support was unrelated to asthma outcomes. 
A link between lower socioeconomic status and asthma exacerbation has also been described. An increase was found in IL-5 and IL-13 levels and eosinophil counts in children from families that rented rather than owned their home. ${ }^{83}$ Moreover, it was reported that the production of IL-13 in children with asthma was inversely correlated with family savings and annual family incomes.

Kopel et $\mathrm{al}^{84}$ showed that children whose caregivers felt their neighborhood to be unsafe have a greater rate of uncontrolled asthma than those living in neighborhoods considered to be safe. It was also reported $^{85}$ that a perceived stress level in parents (as evaluated by a self-report questionnaire) is associated with increased levels of asthma-relevant inflammatory markers. Data of clinical studies ${ }^{86,87}$ support the hypothesis that chronic stress leads to a reduced ability of cortisol to regulate cytokine activity and subsequent airway inflammation. Thus, acute and chronic stress exposures have been related to decreased expression of genes encoding for GR (by 5.5-fold) and the $\beta_{2}$-adrenergic receptor (by 9.5-fold) in leukocytes of children with asthma. ${ }^{86}$ In addition, school-aged children who perceived a low parental presence had a reduced leukocyte response to GCs in vitro. $^{85}$

Research performed in animal models has been used to study the pathophysiological mechanism that participates in stress-induced asthma exacerbation. ${ }^{88-92}$ Accumulating evidence indicates that psychological stress enhanced the frequency, duration, and severity of asthma symptoms by eosinophilic increasing airway inflammatory responses, characterized by a switch toward a Th2-dominant cytokine profile. $^{93,94}$ Furthermore, a Th2 dominant cytokine profile is related to GC resistance. ${ }^{24,32,33}$

The canonical pathways participating in stress response include the hypothalamic-pituitary-adrenal axis and the sympathetic-adrenal-medullary axis. The stress hormones, GCs, epinephrine, and norepinephrine, induce immunologic alterations. This neuroendocrine response amplifies Th2-type immune responses in the lungs via the induction of Th1/Th2 or regulatory $\mathrm{T}$ cell/Th2 imbalance. This response is strongly associated with psychological stress-induced asthma exacerbation ${ }^{14,95}$ and GC resistance. ${ }^{24,32,33}$ Okuyama et $\mathrm{al}^{96}$ showed that a rise of corticosterone levels during stress exposure was implicated in the exacerbated allergic airway response induced by challenge with ovalbumin. The stressed mice challenged with ovalbumin had an increase in eosinophils and lymphocytes in the airways and augmented levels of IL-13 in the lung compared with nonexposed mice. The administration of a GR antagonist and a GC synthesis inhibitor during stress exposure significantly reduced these effects in stressed mice challenged with antigen. Kawano et $\mathrm{al}^{97}$ in a murine model of allergic asthma found that psychological stress exposure avoids the development of respiratory tolerance. The mechanism involved GC-dependent suppression of tolerogenic dendritic cells and regulatory $\mathrm{T}$-cell induction, which, in turn, results in an increased susceptibility to allergic asthma. These findings suggest that psychological stress can potentially increase allergic asthma susceptibility by inhibiting immune tolerance.

All these results indicate a pathophysiological role for the neuroendocrine axis, linking psychological stress with asthma exacerbations. However, GC administration has been widely used for asthma management. To explain this apparent discrepancy of GC's role in allergic inflammation, Ohno ${ }^{14}$ proposed that GCs may play a distinctive role in the regulation of Th2 immune responses depending on several factors, among them the timing, frequency, and location of this hormone's appearance.

\section{THERAPEUTIC APPROACHES TO IMPROVE CORTICOSTEROID SENSITIVITY IN SEVERE ASTHMA}

As noted earlier, resistance to the anti-inflammatory effects of GC is a serious concern that limits the response in asthma treatment. The use of alternative anti-inflammatory treatments is restricted by their side effects. Thus, potential therapeutic strategies involving the development of highly potent GCs or drugs able to interfere with molecular pathways involved in GC resistance are being studied (Table).

\section{Development of Highly Potent GCs}

He et $\mathrm{al}^{98}$ have been developing a series of highly potent GCs, namely VSGC12, VSG158, and VSG159, based on the structural insight into the GR. In particular, the authors developed an extremely potent GC-denominated VSG158. This GC presented the highest potency in avoiding lung airway hyperresponsiveness and lung inflammation in a mouse model of eosinophilic and neutrophilic airway 
Table. Relevant therapeutic strategies under study to reverse glucocorticoid resistance in asthma.

\begin{tabular}{|c|c|c|}
\hline Therapeutic Strategy & Drugs & Pharmacological Effect \\
\hline Highly potent glucocorticoids & VSG $158^{98}$ & $\begin{array}{l}10 \text { times more potent than the most potent } \\
\text { clinical glucocorticoid fluticasone }\end{array}$ \\
\hline Restoration of HDAC-2 function & $\begin{array}{l}\text { IC87114 } \\
\text { Formoterol }^{99} \\
\text { Theophylline }^{99} \\
\text { Antagonist miR-21 }{ }^{100}\end{array}$ & Inhibits $\mathrm{PI} 3 \mathrm{~K} \delta$ \\
\hline Decrease GR phosphorylation & $\begin{array}{l}\text { SB203580 } \\
\text { Antagonist miR9 } \\
\text { Formoterol }^{105}\end{array}$ & $\begin{array}{l}\text { Inhibits p38 MAPK } \\
\text { Increases PP2A activity }\end{array}$ \\
\hline
\end{tabular}

$\mathrm{GR}=$ glucocorticoid receptor; HDAC-2 = histone deacetylase-2; MAPK = mitogen-activated protein kinase; miR = microRNA; $\mathrm{PI} 3 \mathrm{~K} \delta=$ phosphoinositide 3-kinase-delta; PP2A = protein phosphatase $2 \mathrm{~A}$.

inflammation. This compound was 10 times more potent than the current most potent clinical GC, fluticasone furoate, and displayed reduced offtargeting and side effects. In addition, these GCs also display pharmacokinetic properties that are suitable for the inhalation delivery method for asthma treatment. Taking these findings into account, VSG158 could be a promising drug for treating steroid-resistant severe asthma.

\section{Resetting HDAC-2 Function}

HDAC-2 is believed to play a critical role in mediating the anti-inflammatory actions of corticosteroids. Many potential therapeutic approaches to restore HDAC-2 function have emerged from in vitro studies. HDAC-2 activity is diminished by phosphorylation induced by the PI3K pathway. The PI3K $\delta$ isoform has recently been identified as an important upstream kinase in mediating steroid resistance in severe asthma. Inhibitors of PI3K $\delta$, such as such as IC87114, ${ }^{99}$ or nonspecific drugs such as formoterol or theophylline have been shown to be capable of restoring GC response. In addition, an important role of miR-21 in the pathogenesis of asthma and in steroid resistance via PI3K activation was reported. ${ }^{100}$ It was proposed that the development of miRNA-based drugs could constitute a promising therapy to improve treatment of GC-resistant asthma.

\section{p38 MAPK Inhibitors}

Evidence supports a critical role of the MAPK pathway in steroid resistance in severe asthma. Thus, a higher level of p38 MAPK phosphorylation was reported in the PBMCs of GC-resistant patients with asthma compared with patients with GC-sensitive asthma. ${ }^{101}$ The treatment with the p38 MAPK inhibitor SB203580 diminished p38 phosphorylation and mitigated steroid resistance by enhancing dexamethasone-mediated suppression of IL- 8 mRNA expression induced by lipopolysaccharide in PBMCs from GC-resistant patients.

\section{Other Possible Strategies}

Although the debate continues, the role of vitamin D in asthma pathogenesis and steroid responsiveness has recently gained much interest. ${ }^{102}$ As described earlier, vitamin $\mathrm{D}$ deficiency has been associated with reduced lung function and lack of steroid effectiveness in vitro. ${ }^{67,68}$ In addition, vitamin $\mathrm{D}$ has been shown to be effective at restoring GC responsiveness in in vitro models. ${ }^{69}$ Clinical trials are currently underway to determine whether vitamin adjunct therapy can restore clinical GC sensitivity and asthma severity. ${ }^{103,104}$

It was reported that phosphorylation of the GR at Ser226 reduces GR nuclear translocation, resulting in GC insensitivity in patients with severe asthma. ${ }^{105}$ Thus, other possible strategies could include modulating GR activity by using protein phosphatase activators. A recent study identified a protein kinase dual-specificity phosphatase involved in the regulation of corticosteroid sensitivity. In addition, the authors showed that formoterol restores impaired GC 


\section{Clinical Therapeutics}

sensitivity in an in vitro model, suggesting that this phosphatase might be a novel therapeutic target in severe asthma. Moreover, it was shown that inhibition of miR-9 increased both phosphatase $2 \mathrm{~A}$ activity and GR nuclear translocation in macrophages and restored the GC sensitivity in multiple models of GC-resistant airway hyperresponsiveness. ${ }^{106}$

Finally, other possible therapies include: inhibitors of P-glycoprotein, antioxidants to revert oxidative stress effects, inhibition of pro-inflammatory cytokines (eg, interferon- $\gamma$, TNF- $\alpha$, transforming growth factor- $\beta$, IL17A, IL-27, IL-33), and kinase (eg, JNF, ERK, glycogen synthase kinase-3 $\beta$ ) inhibitors. ${ }^{107}$

\section{CONCLUSIONS}

GCs are very effective agents available for the treatment of inflammatory diseases such as asthma. In clinical practice, a number of patients exhibit a poor or absent response even to high doses of GCs, and GC insensitivity in patients with severe disease remains a major clinical problem. Stress profoundly affects the course of airway inflammation. In asthma, evidence suggests that chronic exposure to negative stress induces inflammatory changes, increasing asthma exacerbations and contributing to a worse GC response.

Patients with GC resistance can be treated with other broad-spectrum anti-inflammatory drugs, but in general these drugs have major side effects. Different molecular mechanisms of GC resistance have been described that might be useful in the development of new therapeutic strategies for reversing GC resistance or to sensitize resistant disease to the anti-inflammatory effects of GCs. In this sense, it is important to detect specific biomarkers to help identify patients who are likely to benefit from new therapies. Novel drugs, including highly potent GCs, PI $3 K \delta$ inhibitors to resetting of HDAC-2 function, decrease of GR phosphorylation by p38 MAPK inhibitors, or phosphatase activators, are already in clinical development and therefore might be combined with corticosteroid therapy in the future. In addition, miRs (small noncoding RNA molecules) operate as posttranscriptional regulators providing another level of fine adjustment of GR levels. The experimental findings allow postulating that detection and study of miRNAs seem to be a promising approach to better characterize and treat patients with asthma.

Finally, taking into account that stress is an important external factor that increases asthma exacerbations and contributes to asthma morbidity and mortality, the adequate management of stress could be an important and positive intervention.

\section{CONFLICTS OF INTEREST}

The authors have indicated that they have no conflicts of interest regarding the content of this article.

\section{ACKNOWLEDGMENTS}

This work was supported by grants to Dr. Genaro from the National Research Council of Argentina (CONICET, PIP 00163) and from the National Agency for Science and Technology (ANPCYT, PICT 2016-2727).

Dr. Palumbo was responsible for visualization and writing/review and editing; Mr. Prochnik and Dr. Wald were responsible for writing/review and editing; and Dr. Genaro was responsible for conceptualization and writing/review and editing.

\section{REFERENCES}

1. McEwen BS. Central effects of stress hormones in health and disease: understanding the protective and damaging effects of stress and stress mediators. Eur J Pharmacol. 2008;583:174-185.

2. Di Rosso ME, Sterle HA, Cremaschi GA, Genaro AM. Beneficial effect of fluoxetine and sertraline on chronic stress-induced tumor growth and cell dissemination in a mouse model of lymphoma: crucial role of antitumor immunity. Front Immunol. 2018;9:1341.

3. Palumbo ML, Di Rosso ME, Simon EH, Gonzalez Murano MR, Genaro AM. Altered interferon- $\gamma$ expression in lymphocytes as a potential peripheral marker of chronic stress-induced cognitive deficit. Cytokine. 2018;107: 26-34.

4. Palumbo ML, Trinchero MF, Zorrilla-Zubilete MA, Schinder AF, Genaro AM. Glatiramer acetate reverts stressinduced alterations on adult neurogenesis and behavior. Involvement of Th1/Th2 balance. Brain Behav Immun. 2012;26:429-438.

5. Rubinstein MR, Cremaschi GA, Oliveri LM, Gerez EN, Wald MR, Genaro AM. Possible involvement of stress hormones and hyperglycaemia in chronic mild stress-induced impairment of immune functions in diabetic mice. Stress. 2010;13:384-391.

6. Dhabhar FS. Effects of stress on immune function: the good, the bad, and the beautiful. Immunol Res. 2014;58:193-210.

7. Cohen S, Janicki-Deverts D, Miller GE. Psychological stress and disease. JAMA. 2007;298:1685-1687. 
8. Chung KF, Wenzel SE, Brozek JL, et al. International ERS/ATS guidelines on definition, evaluation and treatment of severe asthma. Eur Respir J. 2014;43:343-373.

9. Castillo JR, Peters SP, Busse WW. Asthma exacerbations: pathogenesis, prevention, and treatment. J Allergy Clin Immunol Pract. 2017;5:918-927.

10. Quax RA, Manenschijn L, Koper JW, et al. Glucocorticoid sensitivity in health and disease. Nat Rev Endocrinol. 2013;9:670-686.

11. Barnes PJ, Adcock IM. Review glucocorticoid resistance in inflammatory diseases. Lancet. 2009;373:1905-1917.

12. Zhou H, Xu M, Qin P, et al. A multicenter randomized openlabel study of rituximab plus rhTPO vs rituximab in corticosteroidresistant or relapsed ITP. Life Sci. 2018;209:383-387.

13. Hew M, Chung KF. Corticosteroid insensitivity in severe asthma: significance, mechanisms and aetiology. Intern Med J. 2010;40:323 $-334$.

14. Ohno I. Neuropsychiatry phenotype in asthma: psychological stressinduced alterations of the neuroendocrine-immune system in allergic airway inflammation. Allergol Int. 2017;66S:S2-S8.

15. Ingawale DK, Mandlik SK, Patel SS. An emphasis on molecular mechanisms of anti-inflammatory effects and glucocorticoid resistance. J Complement Integr Med. 2015;12:1-13.

16. Strehl C, Buttgereit F. Optimized glucocorticoid therapy: teaching old drugs new tricks. Mol Cell Endocrinol. 2013;380:32-40.

17. Arango-Lievano M, Jeanneteau F. Timing and crosstalk of glucocorticoid signaling with cytokines, neurotransmitters and growth factors. Pharmacol Res. 2016;113(pt A):1-17.

18. Jeong JS, Kim SR, Cho SH, Lee YC. Stress: beyond the "type 2/non-type
2 dichotomy": a novel insight on endotyping heterogeneous severe asthma based on endoplasmic reticulum. Int J Mol Sci. 2019;20. pii: E713.

19. Mukherjee M, Svenningsen S, Nair P. Glucocorticosteroid subsensitivity and asthma severity. Curr Opin Pulm Med. 2017;23:78 $-88$.

20. Wu W, Bleecker E, Moore W, et al. Unsupervised phenotyping of Severe Asthma Research Program participants using expanded lung data. J Allergy Clin Immunol. 2014;133:1280-1288.

21. Hakonarson H, Bjornsdottir US, Halapi E, et al. Profiling of genes expressed in peripheral blood mononuclear cells predicts glucocorticoid sensitivity in asthma patients. Proc Natl Acad Sci U S A. 2005;102:14789-14794.

22. Tantisira KG, Lasky-Su J, Harada M, et al. Genome wide association between GLCCI1 and response to glucocorticoid therapy in asthma. N Engl J Med. 2011;365:1173-1183.

23. Ito K, Tomita T, Barnes PJ, Adcock IM. Oxidative stress reduces histone deacetylase (HDAC)2 activity and enhances IL-8 gene expression: role of tyrosine nitration. Biochem Biophys Res Commun. 2004;315:240-245.

24. Sher ER, Leung DY, Surs W, et al. Steroid-resistant asthma. Cellular mechanisms contributing to inadequate response to glucocorticoid therapy. J Clin Invest. 1994;93:33-39.

25. Vreugdenhil E, Berezikov E. Finetuning the brain: microRNAs. Front Neuroendocrinol. 2010;31:128-133.

26. Ledderose C, Möhnle P, Limbeck E, et al. Corticosteroid resistance in sepsis is influenced by microRNA124-induced downregulation of glucocorticoid receptor- $\alpha$. Crit Care Med. 2012;40:2745-2753.

27. Heffler E, Allegra A, Pioggia G, Picardi G, Musolino C, Gangemi S. MicroRNA profiling in asthma: potential biomarkers and therapeutic targets. Am J Respir Cell Mol Biol. 2017;57:642-650.

28. Koper JW, van Rossum EF, van den Akker EL. Glucocorticoid receptor polymorphisms and haplotypes and their expression in health and disease. Steroids. 2014;92:62-73.

29. Hamid QA, Wenzel SE, Hauk PJ, et al. Increased glucocorticoid receptor beta in airway cells of glucocorticoid insensitive asthma. Am J Respir Crit Care Med. 1999;159: 1600-1604.

30. Sousa AR, Lane SJ, Cidlowsk JA, Staynov DZ, Lee TH. Glucocorticoid resistance in asthma is associated with elevated in vivo expression of the glucocorticoid receptor betaisoform. J Allergy Clin Immunol. 2000;105:943-950.

31. Goleva E, Li L, Eves PT, et al. Increased glucocorticoid receptor beta alters steroid response in glucocorticoid-insensitive asthma. Am J Respir Crit Care Med. 2006;173: 607-616.

32. Vazquez-Tello A, Halwani R, Hamid Q, Al-Muhsen S.

Glucocorticoid receptor-beta upregulation and steroid resistance induction by IL-17 and IL-23 cytokine stimulation in peripheral mononuclear cells. J Clin Immunol. 2013;33:466-478.

33. Irusen E, Matthews JG, Takahashi A, Barnes PJ, Chung KF, Adcock IM. p38 mitogenactivated protein kinase-induced glucocorticoid receptor phosphorylation reduces its activity: role in steroid-insensitive asthma. J Allergy Clin Immunol. 2002;109:649-657.

34. Weigel NL, Moore NL. Steroid receptor phosphorylation: a key modulator of multiple receptor functions. Mol Endocrinol. 2007;21: 2311-2319.

35. Galliher-Beckley AJ, Cidlowski JA. Emerging roles of glucocorticoid receptor phosphorylation in modulating glucocorticoid hormone 
action in health and disease. IUBMB Life. 2009;61:979-986.

36. Bhavsar P, Hew M, Khorasani N, et al. Relative corticosteroid insensitivity of alveolar macrophages in severe asthma compared to non-severe asthma. Thorax. 2008;63:784-790.

37. Mercado N, Hakim A, Kobayashi Y, et al. Restoration of corticosteroid sensitivity by p38 mitogen activated protein kinase inhibition in peripheral blood mononuclear cells from severe asthma. PLoS One. 2012;7, e41582.

38. Ismaili N, Garabedia MJ. Modulation of glucocorticoid receptor function via phosphorylation. Ann N Y Acad Sci. 2004; 1024:86-101.

39. Tanaka T, Okabe T, Gondo S, et al. Modification of glucocorticoid sensitivity by MAP kinase signaling pathways in glucocorticoid-induced T-cell apoptosis. Exp Hematol. 2006;34:1542-1552.

40. Oakley RH, Cidlowski JA. Cellular processing of the glucocorticoid receptor gene and protein: new mechanisms for generating tissuespecific actions of glucocorticoids. J Biol Chem. 2011;286:3177-3184.

41. Galigniana MD, Piwien-Pilipuk G, Assreuy J. Inhibition of glucocorticoid receptor binding by nitric oxide. Mol Pharmacol. 1999;55: 317-323.

42. Newton R, Holden NS. Separating transrepression and transactivation: a distressing divorce for the glucocorticoid receptor? Mol Pharmacol. 2007;72:799-809.

43. Loke TK, Mallett KH, Ratoff J, et al. Systemic glucocorticoid reduces bronchial mucosal activation of activator protein 1 components in glucocorticoid-sensitive but not glucocorticoid-resistant asthmatic patients. J Allergy Clin Immunol. 2006;118:368-375.

44. Hew M, Bhavsar P, Torrego A, et al. Relative corticosteroid insensitivity of peripheral blood mononuclear cells in severe asthma. Am J Respir Crit Care Med. 2006;174:134-141.

45. Osoata G, Yamamura S, Ito M, et al. Nitration of distinct tyrosine residues causes inactivation of histone deacetylase 2. Biochem Biophy Res Commun. 2009;384:366-371.

46. Gilliland FD, Islam T, Berhane K, et al. Regular smoking and asthma incidence in adolescents. Am J Respir Crit Care Med. 2006;174:1094 $-1100$.

47. Siroux V, Pin I, Oryszczyn MP, Le Moual N, Kauffmann F.

Relationships of active smoking to asthma and asthma severity in the EGEA study. Epidemiological study on the genetics and environment of asthma. Eur Respir J. 2000;15:470 $-477$.

48. Chalmers GW, MacLeod KJ, Thomson L, Little SA, McSharry C, Thomson NC. Smoking and airway inflammation in patients with mild asthma. Chest. 2001;120:1917 $-1922$.

49. Chaudhuri R, Livingston E, McMahon AD, Thomson L, Borland W, Thomson NC. Cigarette smoking impairs the therapeutic response to oral corticosteroids in chronic asthma. Am J Respir Crit Care Med. 2003;168:1308-1311.

50. Ito K, Lim S, Caramori G, Chung KF, Barnes PJ, Adcock IM. Cigarette smoking reduces histone deacetylase 2 expression, enhances cytokine expression, and inhibits glucocorticoid actions in alveolar macrophages. FASEB J. 2001;15: 1110-1112.

51. McMahon AD, Mackenzie SJ, Thomson NC, et al. Glucocorticoid receptor alpha:beta ratio in blood mononuclear cells is reduced in cigarette smokers. J Allergy Clin Immunol. 2004;114:1475-1478.

52. Leung DY, Bloom JW. Update on glucocorticoid action and resistance. J Allergy Clin Immunol. 2003;111:3-22.

53. Nimmagadda SR, Szefler SJ, Spahn JD, Surs W, Leung DY.
Allergen exposure decreases glucocorticoid receptor binding affinity and steroid responsiveness in atopic asthmatics. Am J Respir Crit Care Med. 1997;155:87-93.

54. Johnston SL. Overview of virusinduced airway disease. Proc Am Thorac Soc. 2005;2:150-156.

55. Caramori G, Ito K, Contoli M, et al. Molecular mechanisms of respiratory virus-induced asthma and COPD exacerbations and pneumonia. Curr Med Chem. 2006;13:2267-2290.

56. Jackson DJ, Sykes A, Mallia P, Johnston SL. Asthma exacerbations: origin, effect, and prevention. J Allergy Clin Immunol. 2011;128: 1165-1174.

57. Papi A, Contoli M, Adcock IM, et al. Rhinovirus infection causes steroid resistance in airway epithelium through nuclear factor $\kappa \mathrm{B}$ and $\mathrm{c}$-Jun $\mathrm{N}$-terminal kinase activation. J Allergy Clin Immunol. 2013;132: 1075-1085.

58. Li LB, Goleva E, Hall CF, Ou LS, Leung DY. Superantigen-induced corticosteroid resistance of human $T$ cells occurs through activation of the mitogen-activated protein kinase kinase/extracellular signal-regulated kinase (MEK-ERK) pathway. J Allergy Clin Immunol. 2004;114:1059 -1069 .

59. Sin DD, Sutherland ER. Obesity and asthma. Thorax. 2008;63:1018 -1023 .

60. Taylor B, Mannino D, Brown C, Crocker D, Twum-Baah N, Holguin F. Body mass index and asthma severity in the National Asthma Survey. Thorax. 2008;63:14 -20 .

61. Peters-Golden M, Swern A, Bird SS, Hustad CM, Grant E, Edelman JM. Influence of body mass index on the response to asthma controller agents. Eur Respir J. 2006;27:495 -503 .

62. Sutherland ER, Goleva E, Strand M, Beuther DA, Leung DY. Body mass and glucocorticoid response in 
asthma. Am J Respir Crit Care Med. 2008;178:682-687.

63. To Y, Ito K, Kizawa Y, et al. Targeting phosphoinositide-3kinase-d with theophylline reverses corticosteroid insensitivity in COPD. Am J Respir Crit Care Med. 2010;182: 897-904.

64. Xystrakis E, Kusumakar S, Boswell S, et al. Reversing the defective induction of IL-10-secreting regulatory $\mathrm{T}$ cells in glucocorticoid resistant asthma patients. J Clin Invest. 2006;116:146-155.

65. Urry Z, Chambers ES, Xystrakis E, et al. The role of $1 \mathrm{a}, 25$ -

dihydroxyvitamin D3 and cytokines in the promotion of distinct Foxp3(1) and IL-10(1) CD4(1) T cells. Eur J Immunol. 2012;42:2697 -2708 .

66. Alcorn JF, Crowe CR, Kolls JK. TH17 cells in asthma and COPD. Annu Rev Physiol. 2010;72:495-516.

67. Sutherland ER, Goleva E, Jackson LP, Stevens AD, Leung DY. Vitamin D levels, lung function, and steroid response in adult asthma. Am J Respir Crit Care Med. 2010:699 -704 .

68. Brehm JM, Celedon JC, SotoQuiros ME, et al. Serum vitamin D levels and markers of severity of childhood asthma in Costa Rica. Am J Respir Crit Care Med. 2009;179: 765-771.

69. Zhang $Y$, Leung DY, Richers BN, et al. Vitamin D inhibits monocyte/ macrophage proinflammatory cytokine production by targeting MAPK phosphatase-1. J Immunol. 2012;188:2127-2135.

70. Wainwright NW, Surtees PG, Wareham NJ, Harrison BD. Psychosocial factors and incident asthma hospital admissions in the EPICNorfolk cohort study. Allergy. 2007;62:554-560.

71. Koyanagi K, Koya T, Sasagawa M, et al. Niigata Asthma Treatment Study Group. An analysis of factors that exacerbate asthma, based on a
Japanese questionnaire. Allergol Int. 2009;58:519-527.

72. Plourde A, Lavoie KL, Raddatz C, Bacon SL. Effects of acute psychological stress induced in laboratory on physiological responses in asthma populations: a systematic review. Respir Med. 2017;127:21-32.

73. Sandberg S, Jarvenpaa S, Penttinen A, Paton JY, McCann DC. Asthma exacerbations in children immediately following stressful life events: a Cox's hierarchical regression. Thorax. 2004;59:1046 $-1051$.

74. Sandberg S, Paton JY, Ahola S, et al. The role of acute and chronic stress in asthma attacks in children. Lancet. 2000;356:982-987.

75. Favreau H, Bacon SL, Labrecque M, Lavoie KL. Prospective impact of panic disorder and panic-anxiety on asthma control, health service use, and quality of life in adult patients with asthma over a 4-year followup. Psychosom Med. 2014;76:147 -155 .

76. Oraka E, King ME, Callahan DB. Asthma and serious psychological distress; prevalence and risk factors among US adults, 2001-2007. Chest. 2010;137:609-616.

77. Di Marco F, Santus P, Centanni S Anxiety and depression in asthma. Curr Opin Pulm Med. 2011;17:39 -44 .

78. Chen E, Schreier HM. Does the social environment contribute to asthma? Immunol Allergy Clin N Am. 2008;28:649-664.

79. Chen E, Chim LS, Strunk RC, Miller GE. The role of the social environment in children and adolescents with asthma. Am J Respir Crit Care Med. 2007;176:644-649.

80. Liu X, Olsen J, Agerbo E, et al. Psychological stress and hospitalization for childhood asthma - a nationwide cohort study in two Nordic countries. PLoS One. 2013;8:78816.
81. Sternthal MJ, Jun HJ, Earls F, Wright RJ. Community violence and urban childhood asthma: a multilevel analysis. Eur Respir J. 2010;36:1400-1409.

82. Subramanian SV, Ackerson LK, Subramanyam MA, Wright RJ. Domestic violence is associated with adult and childhood asthma prevalence in India. Int J Epidemiol. 2007;36:569-579.

83. Chen E, Hanson MD, Paterson LQ, Griffin MJ, Walker HA, Miller GE.

Socioeconomic status and inflammatory processes in childhood asthma: the role of psychological stress. J Allergy Clin Immunol. 2006;117:1014-1020.

84. Kopel LS, Gaffin JM, Ozonoff A, et al. Perceived neighborhood safety and asthma morbidity in the school inner-city asthma study. Pediatr Pulmonol. 2015;50:17-24.

85. Wolf JM, Miller GE, Chen E. Parent psychological states predict changes in inflammatory markers in children with asthma and healthy children. Brain Behav Immunol. 2008;22:433 $-441$.

86. Miller GE, Chen E. Life stress and diminished expression of genes encoding glucocorticoid receptor and beta2-adrenergic receptor in children with asthma. Proc Natl Acad Sci U S A. 2006;103:5496-5501.

87. Miller GE, Gaudin A, Zysk E, Chen E. Parental support and cytokine activity in childhood asthma: the role of glucocorticoid sensitivity. J Allergy Clin Immunol. 2009;123:824-830.

88. Joachim RA, Quarcoo D, Arck PC, Herz U, Renz H, Klapp BF. Stress enhances airway reactivity and airway inflammation in an animal model of allergic bronchial asthma. Psychosom Med. 2003;65:811-815.

89. Chida Y, Sudo N, Sonoda J, Hiramoto T, Kubo C. Early-life psychological stress exacerbates adult mouse asthma via the hypothalamus-pituitary-adrenal 
axis. Am J Respir Crit Care Med. 2007;175:316-322.

90. Akiyama H, Amano H, Bienenstock J. Rat tracheal epithelial responses to water avoidance stress. J Allergy Clin Immunol. 2005;116:318 $-324$.

91. Tohda Y, Nanbu Y, Tanaka A, Kubo H, Fukuoka M, Nakajima S. Role of substance $P$ in increased airway hypersensitivity following induced stress in a Guinea pig asthma model. J Investig Allergol Clin Immunol. 1998;8:340-345.

92. Joachim RA, Sagach V, Quarcoo D, Dinh QT, Arck PC, Klapp BF. Neurokinin-1 receptor mediates stress-exacerbated allergic airway inflammation and airway hyperresponsiveness in mice. Psychosom Med. 2004;66:564-571.

93. Chen E, Miller GE. Stress and inflammation in exacerbations of asthma. Brain Behav Immunol. 2007;21:993-999.

94. Wright RJ, Cohen RT, Cohen S. The impact of stress on the development and expression of atopy. Curr Opin Allergy Clin Immunol. 2005;5:23-29.

95. Miyasaka T, Dobashi-Okuyama K, Takahashi T, Takayanagi M, Ohno I. The interplay between neuroendocrine activity and psychological stress-induced exacerbation of allergic asthma. Allergol Int. 2018;67:32-42.

96. Okuyama K, Dobashi K, Miyasaka T, et al. The involvement of glucocorticoids in psychological stress-induced exacerbations of experimental allergic asthma. Int Arch Allergy Immunol. 2014;163:297-306.

97. Kawano T, Ouchi R, Ishigaki T, et al Increased susceptibility to allergic asthma with the impairment of respiratory tolerance caused by psychological stress. Int Arch Allergy Immunol. 2018;177:1-15.
98. He Y, Shi J, Nguyen QT, et al. Development of highly potent glucocorticoids for steroid-resistant severe asthma. Proc Natl Acad Sci U S A. 2019;116:6932-6937.

99. Rossios C, To Y, Osoata G, Ito M, Barnes PJ, Ito K. Corticosteroid insensitivity is reversed by formoterol via phosphoinositide-3-kinase inhibition. BrJ Pharmacol. 2012;167: 775-786.

100. Kim RY, Horvat JC, Pinkerton JW, et al. MicroRNA-21 drives severe, steroid-insensitive experimental asthma by amplifying phosphoinositide 3-kinasemediated suppression of histone deacetylase 2. J Allergy Clin Immunol. 2017;139:519-532.

101. Li LB, Leung DY, Goleva E. Activated p38 MAPK in peripheral blood monocytes of steroid resistant asthmatics. PLoS One. 2015;10, e0141909.

102. Hawrylowicz CM, Santos AF. Vitamin D: can the sun stop the atopic epidemic? Curr Opin Allergy Clin Immunol. 2020;20:181-187.

103. Kalmarzi RN, Ahmadis, Rahehagh R, et al. The effect of vitamin D supplementation on clinical outcomes of asthmatic children with vitamin D insufficiency. Endocr Metab Immune Disord Drug Targets. 2020;20: 149-155.

104. Kang Q, Zhang X, Liu S, Huang F. Correlation between the vitamin D levels and asthma attacks in children: evaluation of the effects of combination therapy of atomization inhalation of budesonide, albuterol and vitamin D supplementation on asthmatic patients. Exp Ther Med. 2018;15:727-732.

105. Kobayashi Y, Ito K, Kanda A, Tomoda K, Mercado N, Barnes PJ. Impaired dual-specificity protein phosphatase DUSP4 reduces corticosteroid sensitivity. Mol Pharmacol. 2017;91:475-481.

106. Li JJ, Tay HL, Maltby S, et al. MicroRNA-9 regulates steroidresistant airway hyperresponsiveness by reducing protein phosphatase $2 \mathrm{~A}$ activity. J Allergy Clin Immunol. 2015;136:462-473.

107. Mei D, Tan WSD, Wong WSF. Pharmacological strategies to regain steroid sensitivity in severe asthma and COPD. Curr Opin Pharmacol. 2019;46:73-81.
Address for correspondence: Ana María Genaro, PhD. Instituto de Investigaciones Biomédicas (UCA-CONICET), Buenos Aires, Argentina. E-mail: amgenaro@yahoo.com.ar 